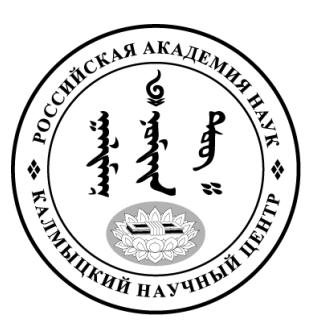

Published in the Russian Federation

Oriental Studies (Previous Name: Bulletin of the Kalmyk Institute for

Humanities of the Russian Academy of Sciences)

Has been issued as a journal since 2008

ISSN: 2619-0990; E-ISSN: 2619-1008

Is. 4, pp. 707-715, 2019

DOI: $10.22162 / 2619-0990-2019-44-4-707-715$

Journal homepage: https://kigiran.elpub.ru

УДК (398.22)

\title{
Матримониальные коллизии в калмыцком эпосе «Джангар» и сказаниях тюрко-монгольских народов Сибири
}

\author{
Данара Владимировна Убушиева ${ }^{1}$, Бальджин Дамринжав ${ }^{2}$ \\ ${ }^{1}$ Калмыцкий научный центр РАН (д. 8, ул. И. К. Илишкина, 358000 Элиста, Российская \\ Федерация) \\ кандидат филологических наук, научный сотрудник \\ ORCID: 0000-0002-5547-4006. E-mail: bib.danara@yandex.ru
}

\author{
${ }^{2}$ Институт национальных литератур Академии общественных наук КНР (5, Цзяньго мэнь нань \\ дацзе, 100732 Пекин, КНР) \\ профессор \\ ORCID: 0000-0002-7338-1030. E-mail: damrinjab@yandex.ru
}

Аннотация. Введение. Эпос «Джангар» относится к героическому типу эпоса, представленного пятью циклами и двумя отдельными песнями. Цель - анализ песен Багацохуровского цикла «Джангара» как раннего цикла, основанного на архаическом эпосе, ядерным образованием которого является сватовство героя. Meтоды. Выявленные мотивы матримониальных коллизий в сравнительно-типологическом анализе со сказаниями о сватовстве алтайцев, бурят и тувинцев, позволили определить инвариантные мотивы архаического эпоса, восходящие к мифологии и предшествующим эпическим традициям. Результаты. При исследовании выявлена роль тестя, который является хозяином водной стихии, чей образ восходит к «охотничьему» эпосу. Описание инвариантной роли тестя стало возможно с привлечением эпосов тюрко-монгольских народов Сибири, так как в калмыцкой эпической традиции данный образ представлен рудиментарно. Также выявлено, что в рассмотренных сказаниях, и тексты Багацохуровского цикла не исключение, суженой героя выступает представительница Водного мира, а соперниками, претендующими на суженую богатыря, выступают представители небесного происхождения. Мотивы поиска суженой в другом мире, передвижение Джангар-хана по другим мирам также демонстрирует архаичность цикла. Bblвoдbl. Песни Багацохуровского цикла основаны на инвариантном ядерном мотивном фонде архаического эпоса, как и эпос тюрко-монгольских народов Сибири, сравнение с которым проливает свет на многочисленные древние мотивы или же их рудименты, которые иначе объяснить и описать не представляется возможным. Возможное развитие данного цикла раскрывается в свете теории «первоначального ядра». Путем нарастания и «разбухания» ядерных тем и мотивов архаического эпоса стало возможно образование Багацохуровского цикла героического эпоса «Джангар». Трансформация архаических песен «Джангара» в классический героический эпос происходила в русле общих закономерностей развития эпического творчества.

Ключевые слова: тип, архаический эпос, Багацохуровский цикл эпоса «Джангар», алтайский эпос, бурятский эпос, тувинские сказания, богатырское сватовство, тема, мотив 
Благодарности. Исследование проведено в рамках государственной субсидии — проект «Устное и письменное наследие монгольских народов России, Монголии и Китая: трансграничные традиции и взаимодействия» (№ государственной регистрации АААА-А19-119011490036-1). Для цитирования: Убушиева Д. В. Матримониальные коллизии в калмыцком эпосе «Джангар» и сказаниях тюрко-монгольских народов Сибири. Oriental Studies. 2019;(4):707-715. DOI: 10.22162/2619-0990-2019-44-4-707-715.

UDC (398.22)

\title{
Matrimonial Collisions in the Kalmyk Epic of Jangar and Legends of Siberia's Turko-Mongols
}

\author{
Danara V. Ubushieva ${ }^{1}$, Baljin Damrinjab ${ }^{2}$ \\ ${ }^{1}$ Kalmyk Scientific Center of the RAS (8, Ilishkin St., Elista 358000, Russian Federation) \\ Cand. Sc. (Philology), Research Associate \\ ORCID: 0000-0002-5547-4006. E-mail: bib.danara@yandex.ru \\ ${ }^{2}$ Institute of Ethnic Literature, Chinese Academy of Social Sciences (FL-11, West Wing, 5 Jiannei \\ Dajie, Beijing 100732, People's Republic of China) \\ Professor \\ ORCID: 0000-0002-7338-1030.E-mail: damrinjab@yandex.ru
}

\begin{abstract}
Introduction. The Jangar epic is an essentially heroic composition represented by five cycles and one separate song. Goals. The paper aims to consider songs of the early Baya Tsokhor Cycle of the Jangar based on archaic epic patterns nuclear elements to which being those dealing with the hero's matchmaking. Methods. The revealed nuclear motifs of matrimonial collisions - within a comparative and typological analysis involving matchmaking-related legends of the Altaians, Buryats and Tuvans - allows defining somewhat invariant motifs of the archaic epos that trace their origins back to mythology and previous epic traditions. Results. The research reveals the role of the fatherin-law who acts as a master of waters and whose image goes back to 'hunting' epic patterns. The description of the father-in-law's invariant role became possible due to the use of epic compositions of Siberian Turko-Mongols since the Kalmyk epic tradition contains only rudimentary elements of this image. The paper also shows that in the legends examined-texts of the Baya Tsokhor Cycle being no exception - it is a representative of the water world who acts as the hero's betrothed, the hero here being rivaled by creatures of heavenly origin. Motifs of search of the betrothed in the other world, Khan Jangar's travels through alien worlds also attest to archaic nature of the cycle. Conclusions. Songs of the Baya Tsokhor Cycle are based on the invariant nuclear motif cluster of the archaic epos, as well as epics of Siberian Turko-Mongols, and it is comparison with the latter that sheds light on numerous ancient motifs or their rudiments that cannot be described or explained in any way. A possible development of the cycle gets clearer when viewed through the prism of the 'initial nucleus' theory. So, the Baya Tsokhor Cycle formed as a result of growth and 'volume swell' of nuclear topics and motifs of the archaic epos. The Jangar's archaic songs developed into a classical heroic epic in accordance with general epic development patterns.
\end{abstract}

Keywords: type, archaic epic, Jangar epic, Baya Tsokhor Cycle, Altaian epic, Buryat epic, Tuvan tales, a hero's matchmaking, theme, motif

Acknowledgements. The research was conducted within a government subsidy — project name 'Oral and Written Heritage of Mongolic Peoples of Russia, Mongolia and China: Cross-Border Traditions and Interactions' (State Reg. No. AAAA-A19-119011490036-1).

For citation: Ubushieva D. V., Damrinjab B. Matrimonial Collisions in the Kalmyk Epic of Jangar and Legends of Siberia's Turko-Mongols. Oriental Studies. 2019;(4): 707-715. DOI: 10.22162/26190990-2019-44-4-707-715. 


\section{है}

\section{Введение}

Калмыцкий эпос «Джангар» относится к героическому типу эпоса, где циклизация заключается в «относительно небольших, как правило, „одноходовых“ песен, не связанных сквозным сюжетом» [Неклюдов 2015: 9]. Эпическая традиция калмыков состоит из пяти локальных циклов: Багацохуровского и Малодербетовского, циклов сказителей Овла Эляева, Мукубена Басангова, Давы Шавалиева. Они в свою очередь определяются по времени фиксации - как ранние и поздние. К ранним относят Багацохуровский (1853 г.) и Малодербетовский (1862 г.) циклы эпоса «Джангар».

В данном исследовании предлагаем рассмотреть песни раннего Багацохуровского цикла ${ }^{1}$ как цикла, основанного на архаическом типе эпоса. Ядерное образование архаического эпоса — «богатырское сватовство», сохранившееся в этих песнях, до настоящего время мало изучено. Цикл не содержит отдельных песен о сватовстве, но в прологах к песням «О Хара Кинесе» и «О Замбал хане», в описании предназначенной суженой Джангар-хана, Герензел-хатун, содержится полный набор мотивов, характерных для темы «героическое сватовство». Для выявления архаических корней темы «богатырское сватовство» в песнях одного из ранних циклов «Джангара» в сравнительно-типологическом аспекте привлечены эпические сказания тюрко-монгольских народов Сибири: алтайцев, бурят, тувинцев.

1 Багацохуровский цикл состоит из трех песен: «О Хара Кинесе», «О Шара Мангасе» и «О Замбал хане». Рукописи двух песен «О Хара Кинесе» и «О Шара Мангасе» на ойратском «ясном письме» хранятся в библиотеке Восточного факультета Санкт-Петербургского госуниверситета [РО БВФ СПбГУ. Calm. С. 17. Ед. хр. 1770. Л. 1-28. Строки 30-31]. Рукопись третьей песни «О Замбал хане» также зафиксирована на «ясном письме» и хранится в Научном архиве Русского географического общества в Санкт-Петербурге под названием «Песни и сказки калмыцкого народа Астраханской губернии Багацохуровского улуса» [НА РГО. Оп. 1. Р. 53. Д. 15].

\section{Основная часть}

В. Я. Пропп обозначает русские былины о сватовстве как «догосударственный» эпос [Пропп 1958: 88]. Сватовство Садко к дочери морского царя определено «древнейшим стержнем песни» [Пропп 1958: 87].

В. М. Жирмунским изучено сказание об Алпамыше в сравнительно-историческом разрезе с тюрко-монгольскими эпосами [Жирмунский 1960]. Исследователь заключает, что в эпической биографии героя, сватовство занимает одно из важнейших мест [Жирмунский 1960: 218].

Б. Н. Путилов в сравнительно-типологическом аспекте исследовал песни русского и южнославянского героических эпосов [Путилов 1971], в которых также рассмотрено героическое сватовство. По мнению Б. Н. Путилова, в архаических памятниках «...важное место занимают мотивы поисков героем невесты-суженой и борьбы за нее» [Путилов 1971:126].

Е. М. Мелетинский, исследовав архаический эпос тюрко-монгольских народов Сибири, называет героическое сватовство универсальной темой древнейших эпосов [Мелетинский 2004:257].

А. Ш. Кичиков, изучив песни калмыцкого эпоса «Джангар» в сравнительно-типологической характеристике с архаическими сказаниями тюрко-монгольской эпической традиции, заключает, что «...тема сватовства, заимствованная у предшествующей, тууль-улигерной, эпической традиции, как и тема борьбы с чудовищами, занимает подчиненное, периферийное положение (всего в двух главах из 26), претерпев крайнюю степень трансформации» [Кичиков 1997: 205].

В исследовании Е. Э. Хабуновой отдельная глава посвящена женитьбе богатыря, которая рассматривается в трех версиях эпоса «Джангар» (калмыцкой, синьцзян-ойратской и монгольской). Автор предполагает, что частота константы «,kuu'k avh“ (взять невесту) дает основание говорить о том, что „история добычи невесты“, < ..> могла составить центральное ядро архаического эпоса, предшествовавшего калмыцкому героическому эпосу „Джангар“»] [Хабунова 2006: 65-66]. 
Б. Б. Манджиевой исследован репертуap сказителя Давы Шавалиева [Манджиева 2018], изучены композиционное строение, мотивы, общие места и поэтические формулы эпических песен. В работе проведен сравнительно-сопоставительный анализ песни «Хоңһрин гер авлһна бөлг» ('Песнь о женитьбе Хонгора') Д. Шавалиева и О. Эляева, основанные на теме «богатырского сватовства» [Манджиева 2018: 34-38].

Сюжеты о героическом сватовстве в синьцзян-ойратском «Джангаре» рассмотрены Ц. Б. Селеевой. Автором, наряду с сюжетообразующими общими элементами, выявлены особенности структуры сюжета героического сватовства в национальной эпике ойратов Синьцзяна [Селеева 2019].

Алтайский героический эпос, по мнению С. С. Суразакова, условно делится на три цикла: 1) борьба с чудовищами, 2) борьба с обитателями подземного мира и 3 ) о сватовстве [Суразаков 1985]. Тема же «богатырского сватовства» присутствует во всех эпических циклах, включая и «охотничий» эпос [Суразаков 1985: 54].

Бурятские эпические сказания, скрупулезно исследованные учеными, также относятся к архаическим. М. И. Тулохонов отмечает, что «Сюжетную основу улигеров составляют две ведущие темы: 1) борьба богатыря с чудовищами и врагами; 2) сватовство и женитьба героя и связанные с ними богатырская поездка и испытания женихов» [Тулохонов 1991: 19].

Изучение тувинского эпоса также имеет свою историю, архаичность сказаний подтверждена многочисленными исследованиями. Л. В. Гребнев выделяет три группы в тувинских сказаниях. Сюжеты первой группы сказаний основаны на подвигах, совершаемых в борьбе за суженую [Гребнев 1960].

С. М. Орус-оол подробно изучены параллели калмыцкого эпоса «Джангар» с эпическими сказаниями тувинцев, алтайцев, хакасов, шорцев и бурят. Параллели обнаружены как в мотивах и персонажах сказочно-мифологического пласта эпоса, так и в поэтике. Эти сходства исследователь объясняет «... древними, не прерывающимися культурно-историческими контактами, общностью исторических судеб. Духовная жизнь этих народов развивалась на базе сходных поверий, общих религиозных воз- зрений: шаманизма и ламаизма (тувинцы, буряты, калмыки), что и предопределило общность традиций и обычаев, моральноэтических норм» [Орус-оол 2011: 43-44].

Тема богатырского сватовства в Багацохуровском цикле «Джангара» ранее не исследовалась. Проведенная нами реконструкция архаического эпоса [Убушиева 2019] по системе А. Ш. Кичикова [Кичиков 1997] выявила в песнях Багацохуровского цикла тему богатырского сватовства как ядерное образование архаического эпоса. Это позволяет нам провести более подробное исследование инвариантных мотивов, связанных с матримониальными коллизиями. Для расшифровки скрытых, рудиментарных эпических кодов привлечены архаические эпические сказания алтайцев, бурят и тувинцев.

Отправным моментом матримониальных коллизий в эпосе является поездка героя в поисках предназначенной суженой. Таким же образом поступает и Джангар-хан: I песня Багацохуровского цикла (далее - Б. Ц.) -5 (16) ${ }^{2}$ törīn dörbōn xāni

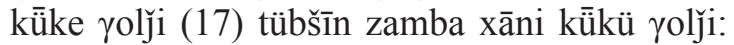
enggīn döčin xoyor noyoni küke (18) yolj̄i: abxu zöbtei küke olǰi yadād [РО БВФ СПбГУ. Calm. С. 17. Л. 5] 'Отвергнув дочерей четырех державных ханов, / Отвергнув дочь Тюбшин Замба хана, / Отвергнув дочерей местных сорока двух нойонов/ Не найдя предназначенную ему девушку'3; III песня Б. Ц. - 15 (10) aliki (11) oronāsa abči xatn keqsenbi geküni (12) törīn dörbön xāni küke yoly̌i enggīn (13) enggīn döčin xoyor noyoni küke yolǰi [НА РГО. Оп. 1. Р. 53. Д. 15. Л. 15] 'Если говорить о том, из какой страны взял, / Отвергнув дочерей четырех державных ханов, / Отвергнув дочерей местных сорока двух нойонов'.

Цикл не демонстрирует мотивировки предназначенности суженой. Б. Н. Путиловым отмечено, что предназначенность в архаическом эпосе не мотивируется, но может быть предписана волею свыше, или может быть записана в Книге судеб [Путилов 1971: 126]. В алтайском эпосе о суженой сообщают родители богатыря, в бурятском и тувинском эпосе начертано в Книге судеб.

\footnotetext{
2 Первая цифра обозначает страницу рукописи, вторая цифра в скобках - номер строки.

3 Здесь и далее перевод автора данной статьи.
} 
Следующий мотив - Поиски жены. «В архаическом эпосе герой едет к невесте долго и трудно, преодолевая на своем пути многочисленные препятствия, в том числе фантастического и мифологического характера, различные магические рубежи ...» [Пропп 1958: 136]. Этот архаичный мотив в цикле показан через описание препятствий и сложностей на пути Джангар-хана к суженой: III песня Б. Ц. — 15 (19) yurban

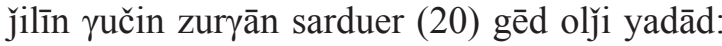
aranzala zērdēn (21) ecēgēd: utu zandan armān ūryal-(22) ǰi čirēd: uryuqsan arban tabuni (23) sara metü dürüng ulān čirēni ünüsün (24) önggötei bolj̄i zobād 'B течение трёх лет / Тридцать шесть месяцев / Кружился, не мог отыскать, / Аранзала Зерде измучив, / Длинное сандаловое копье / Таща, словно укрюк, / Словно луна пятнадцатой ночи, / Красивое лицо его / Исстрадалось и посерело, как пепел’ [НА РГО. Оп. 1. Р. 53. Д. 15. Л. 15].

К примеру, в тувинском сказании «Хунан Кара» расстояние до места обитания суженой описано следующим образом: «[Дочь] Узун-Сарыг-хана с [берега моря] Ус, / [Живущего] прямо в северной стороне / Возле моря Ус, / В далекой земле, / Какую и предкам отца / Вспомнить - и не вспомнить, / [Куда] холощенный верблюд / Пойдет - не дойдет, / Докуда и булатно-стальные копыта / Аранчулы [не выдержат-] / Расплавятся, [либо] сотрутся-износятся〉 [Тувинские героические сказания 1997: 97].

Далее следует мотив «Получение вести о суженой», имеющий в цикле ёмкое описание. Золотой воробей, исполняющий роль чудесного помощника и представляющий иное царство, приносит Джангар-хану весть о суженой: III песня Б. Ц. - 15 (24) öndör cayān (25) ūlain oroi dēre yarči xarūl xar- (26) ji baiba: baitulani mönggön jibirtei (27) altān ödötei boqšoryoi dēre teng- (28) gerēr niseǰi irēd: šobūni kelēr (29) kelbe: yazādaki yalab šartū tenggesīn 16 (1) tere tala nutuqluqsan: očirtu altan (2) ūlutai: oron-du ügei $\gamma$ urban juinda- (3) manitai: güši zambai xāni kükīgi: (4) tenggerīn köbün burxan cayān gedeq (5) künkü čārabn geji bainei: abaxu (6) zöbtei gergen čini tere gebe 'Взобравшись на вершину Белой горы, / Стал осматривать. / Когда осматривал, с серебряными крыльями / С золотым опереньем воробей / Прилетел сверху, с небес, / Раскрыв клюв, / Сказал на птичьем языке: / Внешнего моря Шарту / На той сто- роне расположившегося, / Владеющего драгоценной горой Алтан, / И чиндамани, которого больше нет во всем мире / Дочь Гюши Замба хана / Сын тенгрия, зовущийся Бурхан Цаган, / Хочет насильно взять в жёны, / Тебе предназначенная супруга она, - сказал' [НА РГО. Оп. 1. Р. 53. Д. 15. Л. 15-16].

Такая отмеченная В. Я. Проппом функция птицы, как перенос героя в иное царство [Пропп 2004: 140], трансформирована в настоящем цикле в эпическом ключе, маркером перехода в иное царство является пограничная гора: І песня Б. Ц. - 5 (21)

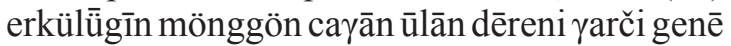
‘Эркулюкской серебряной Белой горы / На вершину взобрался' 'РО БВФ СПбГУ. Calm. С. 17. Л. 5]; III песня Б. Ц. - 15 (24) öndör

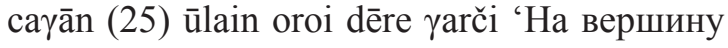
высокой Белой горой взобрался; и Внешнее море' [НА РГО. Оп. 1. Р. 53. Д. 15. Л. 15]; I песня Б. Ц. -5 (23) cāda biyidēn xalēxani nain tabun sarai (24) örgön kītün xara tengges öröu söröu xoyor urusxaltei: urusxulduni (25) üküriyin dungge xara čilūn biye biyen gübdelden: ulān yal badarād: ūlān (26) dungge cayān doligēn undū sundū cokād: nāda biyen ergeni dolōn mingyan (27) alda yalīn ulān enge: utuyān ire iremeqtei: tere tenggesīn ter (28) talani 'По ту сторону посмотрел / В восемьдесят месяцев / Широкое холодное чёрное море / C противоположным течением. / В этом течении чёрные камни величиной с корову / Бились друг об друга,/ Иссекая красный огонь. / Белые волны величиной с гору / Бились туда-сюда. / Берег этой стороны / Семь тысяч саженей / Огненно-красный берег / С краями как лезвие / Расположившийся на той стороне того моря' [РО БВФ СПбГУ. Calm. С. 17. Л. 5]; III песня Б. Ц. 15 (29) yazādaki yalab šartū tenggesīn 16 (1) tere tala nutuqluqsan 'Внешнего моря Шарту, / На той стороне расположившегося’ [НА РГО. Оп. 1. Р. 53. Д. 15. Л. 15-16].

Знаменательно, что суженой Джангар-хана является дочь хозяина Водного мира, как и суженые Гэсэр-хана, Хунан-Каpa: I песня Б. Ц. - 5 (29) naiman mingyan lübsarayān ezen güši zamba xāni küken 'Xoзяина восьми тысяч лубсурга ${ }^{4}$, Гюши Замба хана дочь' [РО БВФ СпбГУ. Calm. С. 17. Л. 5].

${ }^{4}$ Лубсурга (калм. лувсрh) - в монгольской мифологии: дракон, владыка водной стихии и громовержец. 
Поиски предназначенной суженой в ином мире, передвижение Джангар-хана по вертикальной оси мира указывают на сохранившийся древнейший пласт мотивов, отражающий дошаманские верования калмыков.

Е. М. Мелетинским отмечено: «Согласно первобытному миропониманию различные „миры“, в частности Верхний и Нижний, качественно однородны, и люди при жизни могут переходить из одного в другой» [Мелетинский 2004: 315].

В бурятском улигере «Абай Гэсэр» [Абай Гэсэр 1960: 70], Гэсэр три года живет в подводном царстве тестя, владыки вод Лосона. А. И. Уланов, описывая «оборотничество» в улигерах, пишет: «Универсальность „оборотнического“ взгляда дает возможность легко и непринужденно рисовать картины морской жизни и жизни небожителей как „вид“ земной жизни и становится почвой анимизма - одушевления всех вещей и явлений» [Уланов 1963: 219].

Роль отца суженой, тестя Джангар-хана, в теме «богатырского сватовства» настоящего цикла сохранена в рудиментарном виде, более того закодирована, но не утрачена: указано его имя, отмечено, что он является хозяином лубсурга и что он обладатель трех драгоценностей, но далее сюжет не развивает данный образ. Если провести параллель с алтайским сказанием «Кан-Шюлюти», отмеченным С. С. Суразаковым как «... образец архаического произведения о добыче героем жены с выполнением трудных поручений» [Суразаков 1985: 59], то можно расшифровать сохранившиеся рудиментарные представления об отце суженой в теме сватовства рассматриваемого цикла. С. С. Суразаковым отмечено, что «Трудные поручения, даваемые жениху, обличают в отце девушки (будущем тесте героя) человека, стремящегося к владению всеми силами природы, всеми „хозяевами“ ...» [Суразаков 1985: 59].

Приложение данного тезиса к материалам песен Багацохуровского цикла выявило следующее: слово эзн ('хозяин') применяется непосредственно к Джангар-хану, и только единожды, а в песне «О Хара Кинесе», употреблено еще и к его тестю - хозяину лубсурга, т. е. хозяину водной стихии, что отражает синкретизм первобытного сознания. Как замечено С. С. Суразаковым,
«... „хозяева стихий“ (они-то и называются ээзи) чаще всего выступают друзьями и помощниками героев, борьба с ними носит временный характер и всегда заканчивается братанием» [Суразаков 1985: 25]. Инвариантное ядро образов «хозяев» обнаруживается в «охотничьем» эпосе. По мнению С. С. Суразакова, «... сюжеты о встречах, борьбе и братании героев с подобного рода „хозяевами“ < ..> в дошедшем до нас эпосе не выступают самостоятельно, а входят обычно как один из постоянных компонентов в состав сказаний о героическом сватовстве» [Суразаков 1985: 28].

Отталкиваясь от данного объяснения, можно предположить, что древний сказитель, исполнявший песни Багацохуровского цикла, недостаточно четко представил образ и роль отца суженой, но инвариантные ядерные компоненты все же сохранил, и при сравнительном анализе архаических эпосов можно выявить семантическую роль данного персонажа.

Другая ипостась тестя - это устроитель состязаний за суженую. Мотив Участия героя в состязаниях за суженую в цикле не обнаружен, повествование сохранило более древний мотив. Данный мотив является ядерным образованием архаического эпоса, это богоборческий мотив сражения и победы Джангар-хана над сыном Тенгрия: I песня Б. Ц. - 5 (30) tenggerīn köbün burxan cayān gedeq 6 (1) bātur: abn geǰi baqseni alǰi orkōd: naiman mingyan bāturīni köldēn mürgülēd 'Сына Тенгрия, / Богатыря, именуемого Бурхан Цаган, / Который чуть было не взял в жёны [Герензел-хатун], убил, / Восемь тысяч его богатырей / К ногам преклонил' [РО БВФ СПбГУ. Calm. С. 17. Л. 5-6]; ІІІ песня Б. Ц. - 16 (13) tenggerīn (14) köbün burxan cayānigi dolōn mingyan (15) bātartaigīni alj̄i orkōd 'Сына Тенгрия Бурхан Цагана / Вместе с его семью тысячами богатырями убив' [НА РГО. ОП. 1. Р. 53. Д. 15. Л. 16].

Примечательно, что в рассмотренных архаических сказаниях, соперниками, претендующими на суженую богатыря, выступают представители небесного происхождения, к примеру, в тувинском Небесный Демир-Моге, в калмыцком - Сын Тенгрия, Бурхан Цаган.

В сюжете цикла отсутствует описание состязаний за суженую, но следует отметить сохранение двух их видов - скачки 
и стрельба из лука. Оба состязания претерпели трансформацию относительно своего места в сюжете и выведены за пределы богатырского сватовства.

О скачках как о состязании за суженую можно понять из слов богатыря Алтана Чеджи: I песня Б. Ц. - 28 (2) erte uridu ezen ǰanyar: ene gerenǰilēn abaxu caqtan: erkelügīn (3) mönggön cayan ūlār bai kēd uruldaǰi: erebelzeqsen zērdēsu mini: arayam-(4)ǰi turši $\gamma$ arba gēd: kökö daraxani kündü xara alaxār külüq ulanīnin mini ömnö xo-(5)yor belbencegani balbalülalai gēd amīni tatad yabani 'В давние, начальные [времена], когда хозяин Джангар / Эту свою Герензел брал в жёны, / Эркюлюкской серебристой белой горой / Мету сделав, скачки устроил. / «Стремительного Зерде моего / На аркан опередил!» [Джангар-хан] говоря, / Кузнеца Кёке тяжёлым чёрным молотом / Скакуну Улану моему передних ног щиколотки / Разбить заставил, - так вспоминая, придерживает [коня]' [РО БВФ СПбГУ. Calm. С. 17. Л. 28].

Эпизод стрельбы из лука в I песне Б. Ц. - 27 (12) üden engtei kökö (13) jilenggīgi onolād: oqtoryuidu küren aldād (14) büqsurayaqsan uryā zandan moduni oroi dēre (15) uyād unjilsan: kibing šara toryan utusiggiga (16) endel ügei xarbād ' $\mathrm{C}$ дверной косяк толщиной синюю стрелу выпустив, / Стремительно выросшего / Дерева сандал, с верхушки свисающую / Желтую шелковую нить / Без промаха прострелив...' [РО БВФ СПбГУ. Calm. С. 17. Л. 27] можно сравнить со стрельбой из лука в состязаниях за невесту в тувинском сказании «Боктуг-Кириш, Бора-Шээлей»: Богатырь, чья стрела завтра утром сквозь [отверстие в] верблюжьей подвздошной кости пройдет, / [Отверстие в] лисьей подвздошной кости расширит, / Ушко у серебряной иглы обломит, / В ста воловьих возах дрова подожжет, / Железное [изваяние-] хожэ прострелит, / В победители выйдет, / Золотую дангыну Хюн-Хана возьмет [Тувинские героические сказания 1997: 341]. На наш взгляд, представленный эпизод стрельбы из лука в песне «О Хара Кинесе» - рудимент мотива состязаний за суженую. Аналогичных примеров стрельбы из лука в столь изощренную цель в других текстах не обнаружено. Более того, место данного эпизода в сюжете песни имеет явно вставной характер. Древний сказитель сохранил в своей памяти лишь рудименты о героическом сватовстве, отдельные части которого становились составными частями других тем и сюжетов.

Свадебный пир в теме сватовства отсутствует, сам акт бракосочетания сформулирован сверхлаконично: І песня Б. Ц. - 6 (2) mingyan eketü (3) xübil $\gamma \bar{a} \gamma a \bar{r}$ xübilēd abči 'Тысячу раз перевоплощаясь, взял её в жёны' [РО БВФ СПбГУ. Calm. С. 17. Л. 6]; III песня Б. Ц. - 16 (15) gǚši (16) zambain küken arban dolōn nastani abaxi (17) gerenzele xatān abči 'Дочь Гюши Замба / Которую семнадцатилетней должен взять / Ава Герензел хатун свою взял' [НА РГО. Оп. 1. Р. 53. Д. 15. Л. 16].

\section{Выводы}

Матримониальные коллизии, зафиксированные в песнях Багацохуровского цикла, демонстрируют ядерные инвариантные мотивы архаического эпоса, восходящие к мифологии и предшествующим эпическим традициям. Более того, сравнительно-типологический анализ песен цикла и сказаний о сватовстве алтайцев, бурят и тувинцев, также указывает на архаичные корни цикла. При исследовании выявлена роль тестя, который является хозяином водной стихии, чей образ восходит к «охотничьему» эпосу. Описание инвариантной роли тестя стало возможно с привлечением эпосов тюрко-монгольских народов Сибири. Также выявлено, что в рассмотренных сказаниях, и тексты Багацохуровского цикла не исключение, суженой героя выступает представительница Водного мира, а соперниками, претендующими на суженую богатыря, выступают представители небесного происхождения. Мотивы поиска суженой в другом мире, передвижение Джангар-хана по другим мирам также демонстрирует архаичность цикла. Отсюда следует вывод, что песни Багацохуровского цикла основаны на инвариантном ядерном мотивном фонде архаического эпоса, как и эпос тюрко-монгольских народов Сибири, сравнение с которым проливает свет на многочисленные древние мотивы или же их рудименты, которые иначе объяснить и описать не представляется возможным.

Как отмечалось нами ранее, возможное развитие данного цикла раскрывается в свете теории «первоначального ядра» [Убушиева 2019: 67]. Путем нарастания и «разбухания» ядерных тем и мотивов архаиче- 
ского эпоса стало возможно образование Багацохуровского цикла калмыцкого эпоса «Джангар». Трансформация предшествующей архаической традиции в классический

\section{Источники}

Абай Гэсэр 1960 - Абай Гэсэр /сост. А. И. Уланов. Улан-Удэ: Бурятский комплексный научно-исследовательский институт, 1960. $315 \mathrm{c}$.

РО БВФ СПбГУ - Рукописный отдел Библиотеки Восточного факультета Санкт-Петербургского государственного университета. Olon bum burxan üde dumduni üdelegsen... (= Сотни тысяч бурханов в полдень пребывают в покое...) (Рукопись на ойратском языке).

НА РГО - Научный архив Русского географического общества. Песни и сказки Калмыцкого народа Астраханской Губернии Багацохуровского улуса // Оп. 1. Разряд 53. Д. 15. (Рукопись на ойратском языке).

Тувинские героические сказания 1997 - Тувинские героические сказания / сост. С. М. Орус-оол. Новосибирск: Наука, 1997. 584 с.

\section{Sources}

[Abai Geser]. A. I. Ulanov (comp.). Ulan-Ude: Buryat Inst. for Compr. Studies, 1960. 315 p. (In Russ.)

[Hundreds of Thousands of Burkhans Rest in Peace at Noon ...]. In: Manuscript Department, Library of Faculty of Asian and African Studies, St. Petersburg State University. Calm. C. 17 File 1770. Pp. 1-28. Lines 30-31. (In Oirat)

[The Kalmyks of Bagatsokhorovsky Ulus, Astrakhan Governorate: Songs and Fairy Tales]. In: Scientific Archive of the Russian Geographical Society. Ser. 1. Cat. 53. File 15. (In Oir.).

[Tuvan Heroic Legends]. S. M. Orus-ool (comp.). Novosibirsk: Nauka, 1997. 584 p.

\section{Литература}

Гребнев $1960-$ Гребнев Л. В. Тувинский героический эпос (Опыт историко-этнографического анализа). М.: Вост. лит., 1960. 147 с.

Жирмунский 1960 - Жирмунский В. М. Сказание об Алпамыше и богатырская сказка. М.: Восточная литература, 1960. 335 с.

Кичиков 1997 - Кичиков А. Ш. Героический эпос «Джангар». Сравнительно-типологи- героический эпос «Джангар» происходила в русле общих закономерностей развития эпического творчества.

ческое исследование памятника. М.: Вост. лит., 1997.320 с.

Манджиева 2018 - Манджиева Б. Б. Калмыцкий героический эпос «Джангар»: исследование и тексты эпического репертуара Давы Шавалиева. Элиста: КалмНЦ РАН, 2018. $264 \mathrm{c}$.

Мелетинский 2004 - Мелетинский Е. М. Происхождение героического эпоса: Ранние формы и архаические памятники. М.: Вост. лит., 2004. 462 с.

Неклюдов 2015 - Неклюдов С. Ю. Эпос в мировой литературе // Шаги-steps. М.: Российская академия народного хозяйства и государственной службы при Президенте Российской Федерации, 2015. С. 7-22.

Орус-оол 2011 - Орус-оол С. М. «Джангар» и эпос тюрко-монгольских народов // Избранные научные труды. Научное издание. Абакан: ООО «Журналист», 2011. С. 35-44.

Пропп 1958 - Пропn В. Я. Русский героический эпос. 2-е изд., испр. М.: Гослитиздат [Ленингр. отд-ние], 1958. 603 с.

Пропп 2004 - Пропn В. Я. Исторические корни волшебной сказки. М.: Лабиринт, 2004. $332 \mathrm{c}$.

Путилов 1971 - Путилов Б. Н. Русский и южнославянский героический эпос. Сравнительно-типологическое исследование. М.: Наука, 1971. 315 c.

Селеева 2019 - Селеева Ц. Б. «Героическое сватовство» в синьцзян-ойратской версии «Джангара»: сюжетный состав и композиционная структура // Новый филологический вестник. 2019. № 2. С. 65-78.

Суразаков 1985 - Суразаков С. С. Алтайский героический эпос. М.: Наука, 1985. 256 с.

Тулохонов 1991 - Тулохонов М. И. Бурятский героический эпос «Аламжи Мэргэн» // Бурятский героический эпос / сост. М. И. Тулохонов. Новосибирск: Наука, 1991. С. 1037.

Убушиева 2019 - Убушиева Д. В.Мотивы «тууль-улигера» (архаического эпоса) в героическом эпосе «Джангар» // Новый филологический вестник. 2019. № 1 (48). С. 5769. 
Уланов 1963 - Уланов А. И. Бурятский героический эпос. Улан-Удэ: Бурятск. кн.изд-во, $1963.220 \mathrm{c}$.

Хабунова 2006 - Хабунова Е. Э. Героический эпос «Джангар»: поэтические константы богатырского жизненного цикла (сравнительное изучение национальных версий). Ростов-н/Д: Изд-во СКНЦ ВШ, 2006. 256 с.

\section{References}

Grebnev L. V. [The TuvanHeroic Epic:an Attempted Historical and Ethnographic Analysis]. Moscow: Vost. Lit., 1960. 147 p. (In Russ.)

Khabunova E. E. [The Heroic Epic of Jangar: Poetic Constants of the Hero's Life Circle (a Comparative Insight into National Versions)]. Rostov-on-Don: North Caucasus Scient. Cent., 2006.256 p. (In Russ.)

Kichikov A. Sh. [The Heroic Epic of Jangar: a Comparative and Typological Study of the Monument]. Moscow: Vost. Lit., 1997. 320 p. (In Russ.)

Mandzhieva B. B. [The Kalmyk Heroic Epic of Jangar: a Study Suppl. with Texts from Dava Shavaliev's Epic Repertory]. Elista: Kalm. Sc. Cent. of RAS, 2018.264p. (In Russ.)

Meletinsky E. M. [Origins of the Heroic Epic: Early Forms and Archaic Monuments]. Moscow: Vost. Lit., 2004. 462 p. (In Russ.)

Neklyudov S. Yu. The epic in world literature. Shagi/Steps. 2015. Vol. 1. No. 2. Pp. 7-22. (In Russ.)
Orus-ool S. M. The Jangar and epic of the TurkoMongol. In: [Selected Scholarly Works: an Academic Edition]. Abakan: Zhurnalist, 2011. Pp. 35-44. (In Russ.)

Propp V. Ya. [Historical Roots of the Magic Fairy Tale]. Moscow: Labirint, 2004. 332 p. (In Russ.)

Propp V. Ya. [The Russian Heroic Epic]. $2^{\text {nd }}$ ed., rev. Moscow: Goslitizdat, 1958. 603 p. (In Russ.)

Putilov B. N. [The Russian and South Slavic Heroic Epic: a Comparative and Typological Study]. Moscow: Nauka, 1971. 315 p. (In Russ.)

Seleeva Ts. B. 'Heroic matchmaking' in XinjiangOirat version of 'Dzhangar': story construction and compositional structure. The New Philological Bulletin. 2019. No. 2. Pp. 65-78. (In Russ.)

Surazakov S. S. [The Altaian Heroic Epic]. Moscow: Nauka, 1985. 256 p. (In Russ.)

Tulokhonov M. I. The Buryat heroic epic of Alamzhi Mergen. In: [The Buryat Heroic Epic]. M. I. Tulokhonov (comp.). Novosibirsk: Nauka, 1991. Pp. 10-37. (In Russ.)

Ubushieva D. V. Motives of 'tuul-uliger' (the archaic epos) in the heroic epos 'Dzhangar'. The New Philological Bulletin. 2019. No. 1 (48). Pp. 57-69. (In Russ.)

Ulanov A. I. [The Buryat Heroic Epic]. Ulan-Ude: Buryat Book Publ., 1963. 220 p. (In Russ.)

Zhirmunsky V. M. [The Tale of Alpamysh and the Heroic Tale]. Moscow: Vost. Lit., 1960. 335 p. (In Russ.) 